\title{
Thermal Oxidation Stability of Lubricating Greases
}

\author{
Wojciech Krasodomski ${ }^{1}$, Agnieszka Skibińska ${ }^{1 *}$, Magdalena Żółty ${ }^{1}$ \\ 1 Oil and Gas Institute - National Research Institute, ul. Lubicz 25A, 31-503 Cracow, Poland \\ * Corresponding author's e-mail: skibinska@inig.pl
}

\begin{abstract}
Four base oils of different chemical nature were subjected to the oxidation processes using the ASTM D 8206-18 method. On the basis of these oils, three different types of lubricating greases were manufactured: lithium, silica and polyurea lubricating greases. The samples of the lubricating greases were also oxidized in accordance with ASTM D 8206-18. The obtained values of thermal oxidation stability were compared. The FTIR spectra were recorded for all the samples after the oxidation process. On the basis of the analysis of the results from the oxidation stability tests and the FTiR spectra (including differential ones), the groups of base oils and lubricating greases produced with their participation that demonstrate the best and the worst resistance to degradation processes as a result of the oxidation reaction, were determined.
\end{abstract}

Keywords: thermal oxidation stability, lithium and silica and polyurea lubricating greases

\section{INTRODUCTION}

Under the operating conditions, lubricating greases are subject to a number of factors that cause their destruction. These factors are shear stresses, pressure, loads, and varying operating conditions, especially temperature changes with simultaneous contact with air. Physical degradation includes all the physical changes in the lubricating grease during use. It is an irreversible process associated with permanent changes in the structure of the lubricating grease. This includes the mechanical processes that cause damage to the structure of the thickener, increase in the base oil separation and evaporation, as well as contamination of the lubricating grease. Chemical degradation includes all chemical reactions within the lubricating grease, such as base oil oxidation, thickener oxidation, and additive depletion. An important issue related to the processes of chemical degradation is the resistance of the lubricating grease to oxidation [1].

Oxidation is the predominant ageing process that directly affects the service life of a lubricating grease. The oxidation process can be presented with a four-stage diagram of radical-chain reactions [2-4]. This mechanism is referred to as the process of self-oxidation, because the main changes in the structure of oil compounds are the result of the reactions taking place, which are catalyzed by the products of subsequent transformations (Table 1).

Initiation of the oxidation reaction is the result of supplying energy to a hydrocarbon molecule in the form of heat, shear stress, or ultraviolet (UV) radiation. The initiation stage can be catalyzed by metal ions. At room temperature, the reaction rate is very slow, but increases significantly above $100^{\circ} \mathrm{C}$. The ease with which radicals can be formed depends on the strength of the $\mathrm{C}-\mathrm{H}$ and $\mathrm{C}-\mathrm{C}$ bonds and the stability of the resulting radicals. During the propagation phase, the alkyl radicals react irreversibly with the oxygen dissolved in oil and form the peroxide alkyl radicals. Another reaction that results in the formation of hydroperoxides and other alkyl radicals is removal of the hydrogen atom from the hydrocarbon molecule. The consequence of this is the branching of the chain. Hydroperoxides split into the alkoxyl and hydroxyl radicals. The activation energy of these reactions is high and, therefore, they occur at temperatures above $150^{\circ} \mathrm{C}$. Radicals 
Table 1. Oxidation reaction diagram

\begin{tabular}{|c|c|c|c|}
\hline No. & & Stage & Reaction \\
\hline 1 & Initiation & initiation of a chain of reactions & $\begin{array}{l}\mathrm{R}-\mathrm{R} \rightarrow \mathrm{R} \cdot+\mathrm{R} \cdot \\
\mathrm{RH} \rightarrow \mathrm{R} \cdot+\mathrm{H} \cdot \\
\mathrm{RH}+\mathrm{M}^{(n+1)+} \rightarrow \mathrm{H}^{+}+\mathrm{R} \cdot+\mathrm{M}^{\mathrm{n}+} \\
\mathrm{M}^{\mathrm{n}+}+\mathrm{O}_{2} \rightarrow M^{(n+1)+}+\mathrm{O}_{2} \cdot-\end{array}$ \\
\hline 2 & Propagation & expansion of the chain of reactions & $\begin{array}{l}\mathrm{R} \cdot+\mathrm{O}_{2} \rightarrow \mathrm{ROO} \cdot \\
\mathrm{ROO} \cdot+\mathrm{RH} \rightarrow \mathrm{ROOH}+\mathrm{R} \cdot \\
\mathrm{HO}_{2} \cdot+\mathrm{RH} \rightarrow \mathrm{H}_{2} \mathrm{O}_{2}+\mathrm{R} \cdot \\
\mathrm{HO}_{2} \cdot+\mathrm{RH} \rightarrow \mathrm{H}_{2} \mathrm{O}^{2} \mathrm{RO} \cdot \\
\mathrm{ROOH}+\mathrm{M}^{(n+1)+} \rightarrow \mathrm{ROO}+\mathrm{M}^{n+}+\mathrm{H}^{+} \\
\mathrm{ROOH}+\mathrm{M}^{\mathrm{n}} \rightarrow \mathrm{RO}+\mathrm{HO}^{-}+\mathrm{M}^{(n+1)^{+}}\end{array}$ \\
\hline 3 & - & branching of the chain of reactions & $\begin{array}{l}\mathrm{ROOH} \rightarrow \mathrm{RO} \cdot+\mathrm{HO} \cdot \\
\mathrm{RO} \cdot+\mathrm{RH}+\mathrm{O}_{2} \rightarrow \mathrm{ROH}+\mathrm{ROO} \\
\mathrm{HO} \cdot+\mathrm{RH}+\mathrm{O}_{2} \rightarrow \mathrm{H}_{2} \mathrm{O}+\mathrm{ROO}\end{array}$ \\
\hline 4 & Termination & end of the chain of reactions & $\begin{array}{l}\mathrm{R} \cdot+\mathrm{R} \cdot \rightarrow \mathrm{R}-\mathrm{R} \\
\mathrm{R} \cdot+\mathrm{ROO} \cdot \rightarrow \mathrm{ROOR} \\
\mathrm{ROO} \cdot \mathrm{ROO} \cdot \rightarrow \mathrm{ROOR}+\mathrm{O}_{2}\end{array}$ \\
\hline
\end{tabular}

react with hydrocarbons to form water, alcohols, as well as more alkoxyl radicals. The secondary and tertiary alkoxyl radicals form aldehydes and ketones, which combine in an acid-catalyzed aldolic condensation reaction. The condensation products can polymerize, which leads to further degradation as well as formation of slurries and lacquer. The combination of radicals terminates these reactions [5].

Two alkyl radicals can form a hydrocarbon molecule, an alkyl radical can bind to the alkyl peroxide radical, thus producing peroxide, and two alkyl peroxide radicals produce peroxide and oxygen. If metals, such as iron and copper, are present, the reaction can be initiated at a much lower temperature. The metal ions can also catalyze the branching reaction [6] (Table 1).

There are many factors that accelerate the oxidation processes. These include water, metals (such as iron and copper), pollutants, and increased aeration. Probably the most critical factor, however, is temperature. Like in many other chemical reactions, the rate of oxidation also increases with temperature. According to the van't Hoff rule, an increase in temperature by $10 \mathrm{~K}$ results in a two- to four-fold increase in the reaction rate. This rule is fulfilled in the case of homogeneous reactions at temperatures up to $500{ }^{\circ} \mathrm{C}[4,5,7]$.

The methods used in the assessment of resistance of oils and lubricating greases to oxidation enable an analysis of the changes in the chemical structure of oil compounds before and after oxidation. The spectral analysis of infrared (IR) and ultraviolet (UV), gel chromatography, gas chromatography combined with mass spectroscopy (GC/MS), and nuclear magnetic resonance
$\left(\mathrm{NMR}{ }^{13} \mathrm{C}\right)$ are used for this purpose. These methods can be used to identify various hydrocarbon oxidation products such as alkylhydroperoxides $\mathrm{ROOH}$, dialkyl peroxides ROOR, alcohols $\mathrm{ROH}$, aldehydes $\mathrm{RCHO}$, ketones $\mathrm{RCOR}^{1}$, diketones $\mathrm{RCOCH}_{2} \mathrm{COR}^{1}$, ketoaldehydes $\mathrm{RCOCH}_{2} \mathrm{CHO}$, and hydroxyketones $\mathrm{RCH}(\mathrm{OH}) \mathrm{CH}_{2} \mathrm{COR}^{1}$.

The thermal oxidation stability of lubricating greases is tested using the classical method of oxidation in a pressure vessel (a so-called bomb) under specific temperature conditions for a specified period of time (usually at 99 or $100{ }^{\circ} \mathrm{C}$ for 100 hours) and the test result is given as the value of oxygen pressure drop. The standardized test methods for assessing the thermal oxidation stability of lubricating greases are: BS 2000-142:1993, FTM 791.3453, IP 142:2015, ASTM D 942-15, DIN 51808:2018-02, PN-C04143:1956 [8-13]. For the first time in 2018, a new standardized method was introduced for the lubricating greases, the so-called rapid oxidation test, in which the time until the induction period (10\% oxygen pressure drop) according to ASTM D 8206-18 is given as the result [14].

In their publications, Azad and Evans $[15,16]$ presented the benefits of combining the results of two research methods: oxidation using the ASTM D 942 method and the FTIR (Fourier Transform Infrared Spectroscopy) analysis when assessing the thermal oxidation stability of lubricating greases. When analyzing the samples of lithium and lithium complex lubricating greases, they pointed to the difficulties in comparing different lubricating greases based on the results obtained using the ASTM D 942 method. The authors also presented the way to obtain more precise information on the resistance of lubricating greases to 
oxidation by performing the FTIR analysis on the samples with the modified ASTM D 942 test using smaller numbers of samples.

In his article [17], Edinger presented the results obtained for 11 samples in the oxidation resistance tests carried out with the RapidOxy (Rapid Small Scale Oxidation Test - RSSOT) device at $160{ }^{\circ} \mathrm{C}$ according to ASTM D 525 and the classic ASTM D 942 method for lubricating greases (at $99{ }^{\circ} \mathrm{C}$, a 100 - and 400 -hours test). The comparison of the results allowed the author to conclude that there is a good correlation between these research methods. Nolan, on the basis of the research results presented in article [18], confirmed the existence of a correlation between the RSSOT method and the traditional lubricating grease oxidation resistance test method according to ASTM D 942.

\section{EXPERIMENTAL PART}

The object of the study involved base oils of various chemical nature, as well as lithium, silica, and polyurea lubricating greases manufactured in the NLGI 2 consistency class on the basis of these oils.

\section{MATERIALS}

The following base oils were used:

- A - a mineral paraffin oil of group I according to the API;

- B - a mineral naphthenic oil of group V according to the API;

- $\mathrm{C}$ and D - synthetic polyalphaolefin oils of group IV according to the API (1:1 ratio);

- E - a synthetic ester oil of group V according to the API.
The characteristics of these oils are presented in Table 2.

On the basis of the A, B, and E base oils, as well as the $\mathrm{C}$ and $\mathrm{D}$ oils (1:1 ratio), the following lubricating greases were manufactured: lithium $(\mathrm{L})$, silica $(\mathrm{K})$, and polyurea $(\mathrm{P})$, in consistency 2 according to the NLGI. The lithium grease was produced in a classic saponification process of 12-hydroxystearic acid with lithium hydroxide. The silica grease was produced by dispersing hydrophobic silica in oil. The polyurea grease is produced by dispersing a ready-made thickener in the oil. Twelve samples of the lubricating greases were produced and their basic properties are presented in Table 3.

\section{TEST METHODS}

The oxidation resistance of the lubricating greases was tested according to ASTM D 8206-18. A glass test vessel was filled with $4 \mathrm{~g}$ of lubricating grease at ambient temperature; the reaction vessel was initially rinsed with oxygen and then filled to the pressure of $700 \pm 5 \mathrm{kPa}$. The test chamber was heated to $140 \pm 0.1{ }^{\circ} \mathrm{C}$. The pressure in the vessel dropped as oxygen was used to oxidize the sample and was recorded at 1 second intervals until the break point was reached - a $10 \%$ drop in pressure. The time elapsing from the beginning of the determination to the break point was an inductive period at the test temperature.

The infrared spectra (FTIR) of the lubricating grease samples were recorded with a Thermo Nicole's IS5 camera. In the case of the transmission spectra, a ZnSe cuvette with a $0.1 \mathrm{~mm}$ thick spacer was used, whereas in the case of the ATR spectra, a diamond crystal was used. The spectra were recorded in the range of $4,000 \mathrm{~cm}^{-1}$ to $550 \mathrm{~cm}^{-1}$.

Table 2. Determined physicochemical properties of the oils

\begin{tabular}{|c|c|c|c|c|c|c|c|}
\hline No. & Characteristics & Unit & $A$ & B & $\mathrm{C}$ & $\mathrm{D}$ & $E$ \\
\hline 1 & $\begin{array}{l}\text { Kinematic viscosity [19] } \\
\text { - at } 40{ }^{\circ} \mathrm{C} \\
\text { - at } 100{ }^{\circ} \mathrm{C}\end{array}$ & $\mathrm{mm}^{2} / \mathrm{s}$ & $\begin{array}{l}86.59 \\
10.24\end{array}$ & $\begin{array}{l}107.2 \\
8.927\end{array}$ & $\begin{array}{l}29.94 \\
5.768\end{array}$ & $\begin{array}{l}402.2 \\
40.58\end{array}$ & $\begin{array}{l}125.4 \\
14.40\end{array}$ \\
\hline 2 & Viscosity index [20] & - & 99 & 28 & 138 & 260 & 155 \\
\hline 3 & Color [21] & - & 1.5 & 2.0 & 0 & 0 & 0.5 \\
\hline 4 & Pour point [22] & ${ }^{\circ} \mathrm{C}$ & -12 & -30 & -66 & -42 & -27 \\
\hline 5 & Acid value [23] & $\mathrm{mg} \mathrm{KOH} / \mathrm{g}$ & 0.015 & 0.010 & 0.045 & 0.145 & 1.569 \\
\hline 6 & Flash point [24] & ${ }^{\circ} \mathrm{C}$ & 220 & 214 & 245 & 287 & 297 \\
\hline 7 & Resistance to oxidation [14] & $\min$ & 420 & 77 & (oils C anc & 1:1 ratio) & 22.5 \\
\hline
\end{tabular}


Table 3. The determined physicochemical properties of the lubricating greases

\begin{tabular}{|l|c|c|c|c|c|}
\hline Properties of the lithium lubricating greases & Unit & LA & LB & LCD & LE \\
\hline Worked penetration at $25^{\circ} \mathrm{C}[25]$ & $\mathrm{mm} / 10$ & 292 & 273 & 279 & 279 \\
\hline Dropping point [26] & ${ }^{\circ} \mathrm{C}$ & 196 & 192 & 198 & 190 \\
\hline Resistance to oxidation [14] & $\mathrm{min}$ & 27.3 & 25.8 & 23.5 & 17.5 \\
\hline Properties of the silica lubricating greases & Unit & $\mathrm{KA}$ & $\mathrm{KB}$ & $\mathrm{KCD}$ & KE \\
\hline Worked penetration at $25^{\circ} \mathrm{C}[25]$ & $\mathrm{mm} / 10$ & 297 & 259 & 273 & 289 \\
\hline Dropping point [26] & ${ }^{\circ} \mathrm{C}$ & $>300$ & $>300$ & $>300$ & $>300$ \\
\hline Resistance to oxidation [14] & $\mathrm{min}$ & 249 & 92 & 32 & 21 \\
\hline Properties of the polyurea lubricating greases & Unit & PA & PB & PCD & PE \\
\hline Worked penetration at 25 ${ }^{\circ} \mathrm{C}[25]$ & $\mathrm{mm} / 10$ & 263 & 277 & 275 & 299 \\
\hline Dropping point [26] & ${ }^{\circ} \mathrm{C}$ & 253 & 242 & 245 & 250 \\
\hline Resistance to oxidation [14] & $\mathrm{min}$ & 269 & 217 & 201 & 141 \\
\hline
\end{tabular}

\section{DISCUSSION OF THE RESULTS - OXIDATION RESISTANCE}

Under the conditions of the oxidation resistance test, the samples were only slightly degraded and the color of the samples did not change significantly. Most likely, during the test performed using the classical test method according to ASTM D942 (which results in a drop in oxygen pressure after $100 \mathrm{~h}$ of test), the test conditions would force strong oxidation of the lubricating greases. In the case of determination by accelerated oxidation, the measurement was completed after a $10 \%$ drop in pressure (from the maximum pressure) before intensive oxidation of the lubricating grease took place.

It was found that out of all the oils, the group I oil according to the API, i.e. the paraffin oil, was characterized by the best thermal oxidation stability, which is associated with its sulfur content.
The naphthenic and polyalphaolefin oils were characterized by 6 to 7 times lower thermal oxidation stability and the ester oil demonstrated the lowest thermal oxidation stability.

All the lubricating grease samples demonstrated a tendency to reflect the thermal oxidation stability of the oils - the lubricating grease made based on paraffin oil is the most stable, the lubricating grease made on the basis of naphthenic oil is less stable, followed by the lubricating grease made on the basis of PAO, with the ester oil being the least stable.

All lithium lubricating greases samples were characterized by similar, very low resistance to oxidation. In the case of this group of lubricating greases, the use of lithium 12-hydroxystearate as the thickener deteriorated the thermal oxidation stability of the base oils. It is most likely associated with the presence of lithium - a metal that is a catalyst for the oxidation process.

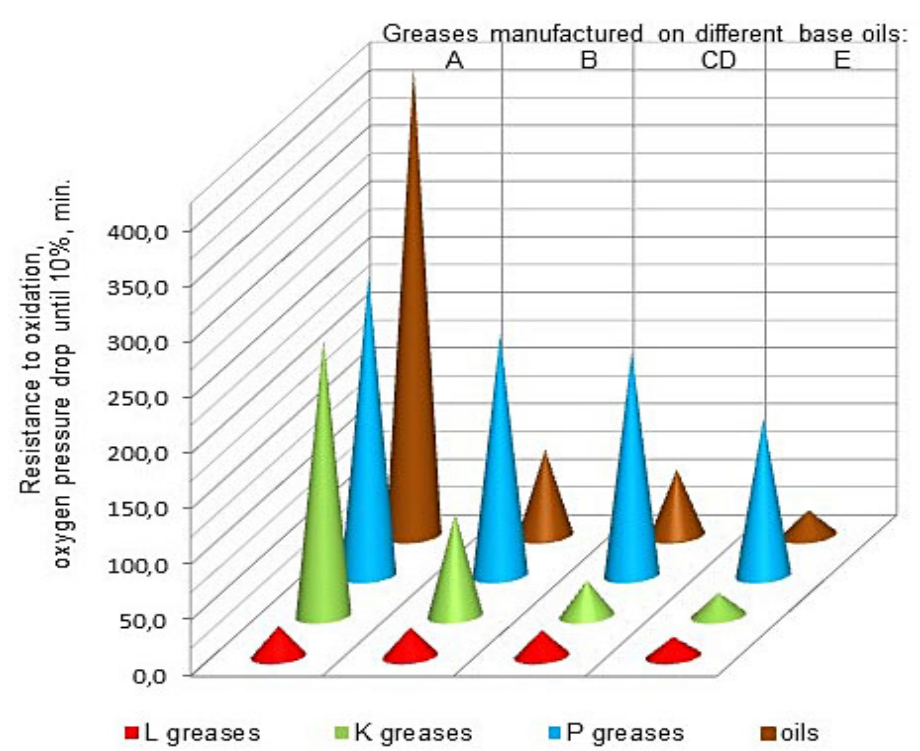

Fig. 1. Resistant to oxidation of the lubricating greases and the base oils 
In the case of the silica lubricating greases, the use of silica as the thickener slightly improved the thermal oxidation stability of the naphthenic base oil, unlike in the case of the other oils used.

The polyurea lubricating grease produced on the basis of paraffin oil proved to be more susceptible to oxidation than the base oil that was used to produce it. The use of a polyurea thickener in other tested base oils increased their thermal oxidation stability 3 to 6 times.

\section{DISCUSSION OF RESULTS - SPECTRAL LUBRICATING GREASE DEGRADATION TESTS}

The FTIR spectra were recorded and analyzed for all oils and lubricating greases as well as their oxidation products and, based on the results, the differential spectra were generated. The results of the FTIR differential spectra analysis of each of the tested lubricating greases are presented in Table 4. Three spectral ranges were analyzed. The spectral changes that were observed are discussed in detail using the example of the sample of LA - a mineral oil based lithium lubricating grease (Fig. 2).

In the FTIR spectrum of a fresh LA lubricating grease (Fig. 3 and 4, blue line) the $\mathrm{COO}^{-}$vibration bands typical for the higher carboxylic acids (lithium soaps) used as salt thickeners, $1,580 \mathrm{~cm}^{-1}, 1,560 \mathrm{~cm}^{-1}, 1,405 \mathrm{~cm}^{-1}$, and $1,340 \mathrm{~cm}^{-1}$, and weak bands, $1,734 \mathrm{~cm}^{-1}$ and $1,715 \mathrm{~cm}^{-1}$, originating from other carboxylic or carboxylic compounds, were observed. The spectrum also shows the hydrocarbon structure bands in the range of $3,000-2,800 \mathrm{~cm}^{-1}, 1,450 \mathrm{~cm}^{-1}, 1,377 \mathrm{~cm}^{-1}$, and $721 \mathrm{~cm}^{-1}$. At the same time, a wide band of the associated hydroxyl groups of about $3,330 \mathrm{~cm}^{-1}$ is present.

In the LA lubricating grease spectrum, after the oxidation resistance test (Figs. 3 and 4, red line), a wide, strong band with a complex structure in the range of 1,800-1,660 $\mathrm{cm}^{-1}$, with a maximum of approx. $1,713 \mathrm{~cm}^{-1}$, typical of carboxylic acid structures, appeared. At the same time, the background was raised in the range of 1,300-1,000 $\mathrm{cm}^{-1}$, which indicated the formation of complex oxidation products containing the $\mathrm{C}-\mathrm{O}$ bonds (alcohols, ethers, peroxides, carboxylic acids, and their derivatives). Due to the increase in the number of hydroxyl groups, the band intensity increased to approx. $3,340 \mathrm{~cm}^{-1}$.

These observations were confirmed by the analysis of the differential spectrum (Fig. 5), on which it is additionally possible to distinguish bands in the range of 1,200-1,000 $\mathrm{cm}^{-1}$ connected to the structures containing single $\mathrm{C}-\mathrm{O}$ bonds.

Analogous analyses were performed for other lubricating greases; however, it should be noted that for the lubricating greases containing the ester base oil (E) the analysis of the spectral range of $1,800-1,660 \mathrm{~cm}^{-1}$ was difficult due to the very strong ester band of approx. $1,745 \mathrm{~cm}^{-1}$.

Table 4. Bands observed in FTIR differential spectra related to the oxidation processes of the tested lubricating greases

\begin{tabular}{|c|c|c|c|c|c|}
\hline \multirow{3}{*}{$\begin{array}{c}\begin{array}{c}\text { Lubricant } \\
\text { sample }\end{array} \\
\text { LA }\end{array}$} & \multicolumn{5}{|c|}{ Position of the bands, $\mathrm{cm}^{-1}$; band intensity, abs $/ 0.1 \mathrm{~mm}$} \\
\hline & \multirow{2}{*}{$\begin{array}{c}\text { Bands } \\
\text { in the range of } \\
3,600-3,100 \mathrm{~cm}^{-1} \\
3,470 / 0.065\end{array}$} & \multicolumn{2}{|c|}{$\begin{array}{c}\text { Bands } \\
\text { in the range of } \\
1,800-1,660 \mathrm{~cm}^{-1}\end{array}$} & \multicolumn{2}{|c|}{$\begin{array}{c}\text { Bands } \\
\text { in the range of } \\
1,200-1,000 \mathrm{~cm}^{-1}\end{array}$} \\
\hline & & & $1,715 / 0.232$ & & $1,090 / 0.284$ \\
\hline LB & $3,488 / 0.022$ & & $1,712 / 0.286$ & & $1,010 / 0.013$ \\
\hline LCD & $3,506 / 0.030$ & $1,749 /-0.126$ & $1,713 / 0.294$ & & $1,046 / 0.010$ \\
\hline LE & $3,450 / 0.192$ & $1,743 * /-$ & $1,719 / 0.983$ & $1,165 /-0.388$ & $1,063 / 0.373$ \\
\hline KA & $3,445 / 0.040$ & & $1,715 / 0.152$ & $-{ }^{* *}$ & $-{ }^{* *}$ \\
\hline KB & $3,410 / 0.029$ & & $1,711 / 0.235$ & $-{ }^{* *}$ & $-{ }^{* *}$ \\
\hline KCD & $3,405 / 0.054$ & & $1,712 / 0.226$ & $-^{\star *}$ & $-^{\star *}$ \\
\hline KE & $3,516 / 0.095$ & $1,746 * /-$ & $1,710 / 0.334$ & $-{ }^{* *}$ & $-{ }^{* *}$ \\
\hline PA & $3,456 / 0.096$ & & $1,716 / 0.156$ & $1,154 / 0.072$ & $1,036 / 0.080$ \\
\hline PB & $3,400 / 0.031$ & & $1,714 / 0.161$ & $1,120 / 0.046$ & $1,065 / 0.040$ \\
\hline PCD & $3,465 / 0.031$ & $1,748 /-0.081$ & $1,717 / 0.164$ & & $1,094 / 0.017$ \\
\hline PE & $3,305 / 0.103$ & $1,746^{\star} /-$ & $1,716 / 0.179$ & & $1,074 / 0.140$ \\
\hline
\end{tabular}

* Too strong bands in the transmission spectrum, the bands in the ATR differential spectrum were evaluated together with the indication whether the change in band absorbance is positive or negative.

** Due to the very strong bands derived from $\mathrm{SiO}_{2}$, it was not possible to assess the bands in the $1,200-1,000 \mathrm{~cm}^{-1}$ range. 




Fig. 2. Band intensity approx. $1,715 \mathrm{~cm}^{-1}$, abs $/ 0.1 \mathrm{~mm}$ in the differential spectrum

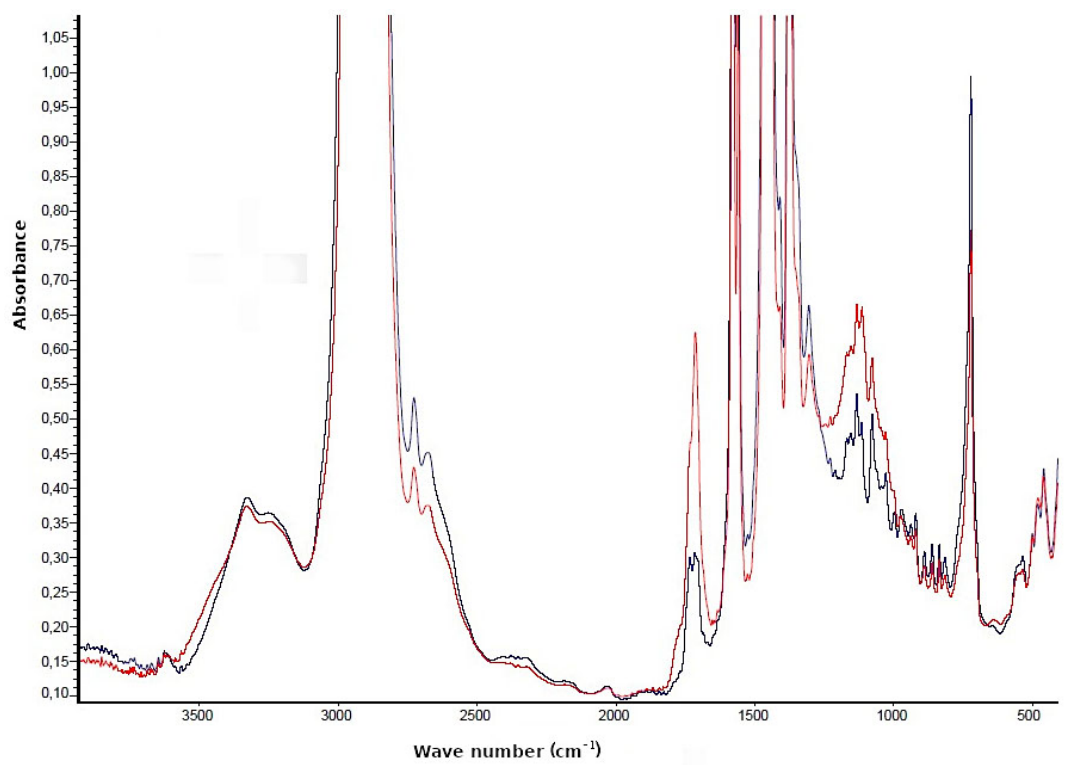

Fig. 3. FTIR spectra of the LA lubricating grease before (blue line) and after (red line) oxidation

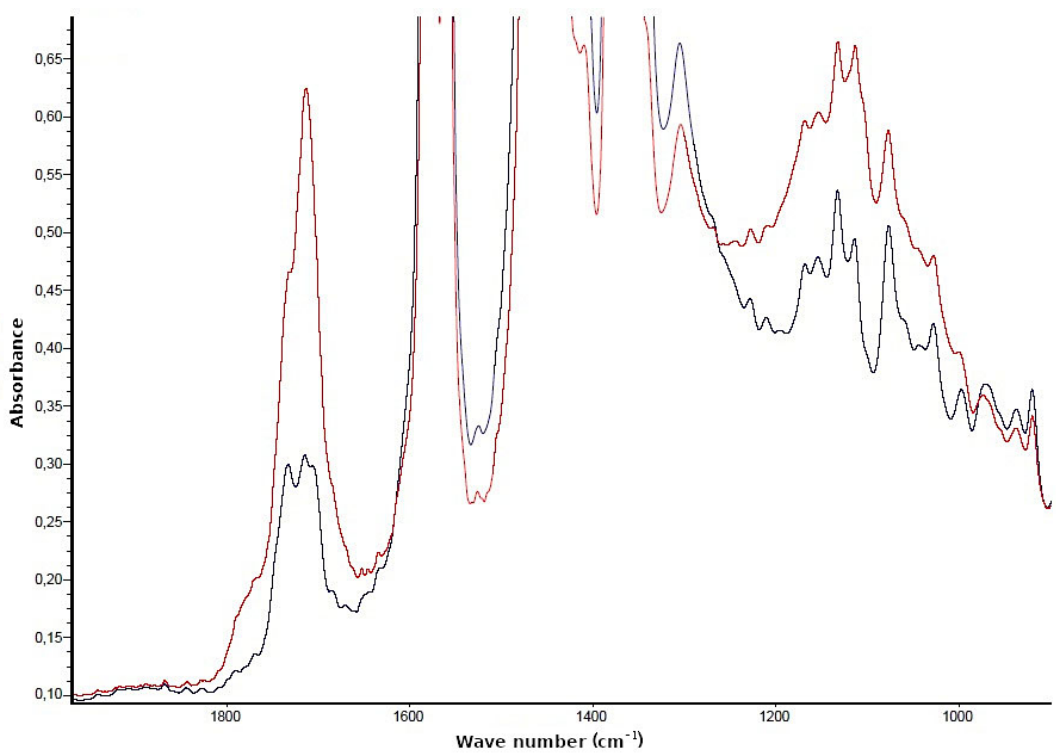

Fig. 4. FTIR spectra in the range of $2,000-1,000 \mathrm{~cm}^{-1}$, of the LA lubricating grease before (blue line) and after (red line) oxidation 


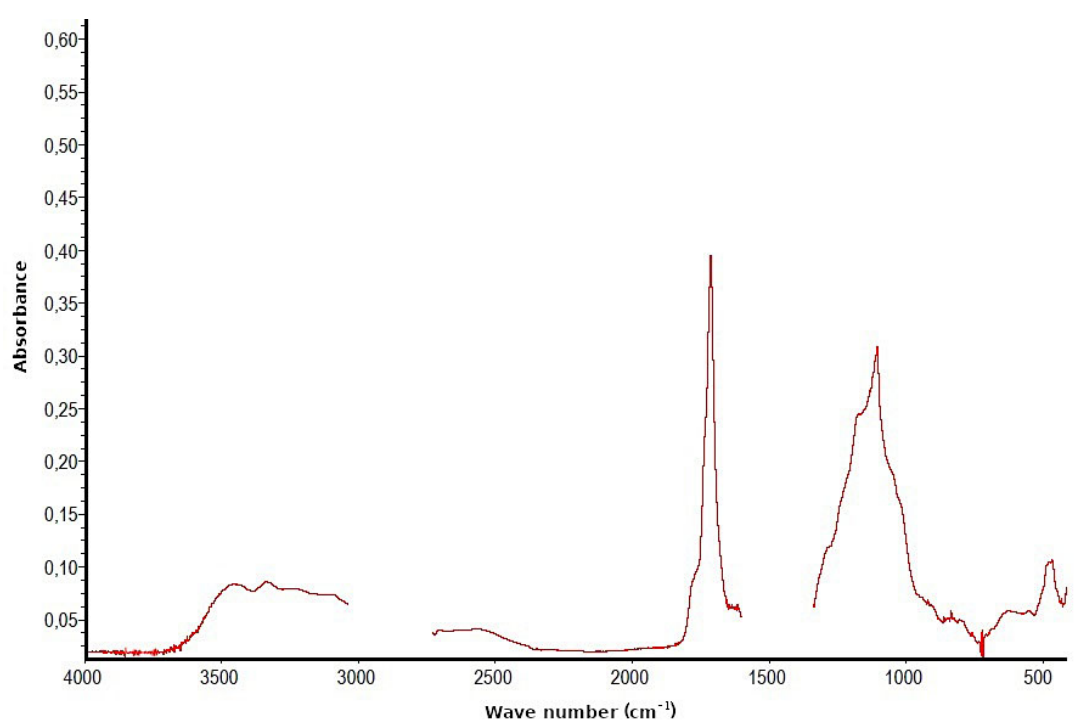

Fig. 5. Differential spectrum of the LA lubricating grease before and after oxidation

The formation of carboxylic structures (bands of about $1,715 \mathrm{~cm}^{-1}$ ) was evaluated on the basis of the differential spectrum obtained by subtracting transmission spectra, whereas the analysis of the ATR spectra confirmed the loss of ester structures.

However, in the case of the lubricating greases containing silica $(\mathrm{K})$ as a thickener, the analysis of the range of $1,200-1,000 \mathrm{~cm}^{-1}$ was difficult due to very strong $\mathrm{SiO}_{2}$ bands that obscured the possible $\mathrm{C}-\mathrm{O}$ bond vibration bands.

The results obtained for the base oils (Table 5) indicate that the mineral oil (A) undergoes the lowest degradation during the determination, the degree of degradation of the oils (B and CD) is slightly higher, and in the ester oil (E) a decrease in the intensity of ester bands with simultaneous strong oxidation of the oil was observed.

In the case of the lithium and silica lubricating greases, the weakest degradation during the test was observed in the paraffin oil-based lubricating grease (A). A similar degree of degradation was observed in the lithium (L) and silica (K) lubricating greases containing the $\mathrm{B}$ and $\mathrm{CD}$ oils, while the ester (E) lubricating greases were oxidized to the greatest extent. In the case of the polyurea lubricating greases, all samples were similarly oxidized.

\section{CONCLUSIONS}

1. Out of all the tested oils, the group I oil according to the API, i.e. the paraffin oil, was characterized by the best thermal oxidation stability, which is associated with its sulfur content. The naphthenic and polyalphaolefin oils were characterized by 6 to 7 times lower thermal oxidation stability and the ester oil demonstrated the lowest thermal oxidation stability.

2. The spectral analysis confirmed that the mineral paraffin oil is the most resistant to oxidation by the ASTM D 8602-18 method, while the ester oil is the least resistant.

3. All the lubricating grease samples demonstrated a tendency to reflect the thermal oxidation stability of the oils - the lubricating grease

Table 5. Bands observed in FTIR differential spectra related to the oxidation processes of the tested oils

\begin{tabular}{|c|c|c|c|c|c|}
\hline \multirow{3}{*}{$\begin{array}{c}\begin{array}{c}\text { Oil } \\
\text { sample }\end{array} \\
\text { A }\end{array}$} & \multicolumn{5}{|c|}{ Position of the bands, $\mathrm{cm}^{-1}$; band intensity, abs $/ 0.1 \mathrm{~mm}$} \\
\hline & \multirow{2}{*}{$\begin{array}{c}\begin{array}{c}\text { Bands } \\
\text { in the range of } \\
3,600-3,100 \mathrm{~cm}^{-1}\end{array} \\
3,380 / 0.015\end{array}$} & \multicolumn{2}{|c|}{$\begin{array}{c}\text { Bands } \\
\text { in the range of } \\
1,750-1,680 \mathrm{~cm}^{-1}\end{array}$} & \multicolumn{2}{|c|}{$\begin{array}{c}\text { Bands } \\
\text { in the range of } \\
1,200-1,000 \mathrm{~cm}^{-1}\end{array}$} \\
\hline & & $1,717 / 0.102$ & & $1,172 / 0.042$ & $1,045 / 0.064$ \\
\hline B & $3,410 / 0.041$ & $1,713 / 0.189$ & & $1,165 / 0.077$ & $1,120 / 0.078$ \\
\hline CD & $3,405 / 0.051$ & $1,748 /-0.255$ & $1,714 / 0.182$ & $1,155 /-0.050$ & \\
\hline$E$ & $3,450 / 0.134$ & $1,742 * /-$ & $1,716 / 0.650$ & & $1,065 / 0.111$ \\
\hline
\end{tabular}

* Too strong bands in the transmission spectrum, the bands in the ATR differential spectrum were evaluated together with the indication whether the change in band absorbance is positive or negative. 
made based on paraffin oil is the most stable, the lubricating grease made on the basis of naphthenic oil is less stable, followed by the lubricating grease made on the basis of PAO, with the ester oil being the least stable.

4. The spectral studies confirmed that in the case of the lithium and silica lubricating greases, the ester oil-based lubricating greases were characterized by the worst resistance to oxidation. In the case of the polyurea lubricating greases, this analysis does not allow distinguishing the level of degradation depending on the base oil used.

\section{REFERENCES}

1. Rezasoltani A., Khonsari M.M., On monitoring physical and chemical degradation and life estimation models for lubricating greases. Lubricants 4 , 2016, 34.

2. Cobb T.W., Gatto V.J., Moehle W.E., Oxidation fundamentals and its application to turbine oil testing. Journal of ASTM International, 3(4), 2006, 1-20.

3. Govender M, WearCheck Techn Bull 2009.

4. Oleksiak S., Żółty M., Wybrane metody badań do monitoringu środków smarowych. Nafta-Gaz, 58(11), 2012, 834-841.

5. Fitch J.C., Gebarin S., Practicing Oil Analysis, May/June, 2006.

6. Beran E., Prace Nauk. Wydziału Chemicznego Politechniki Wrocławskiej 2008.

7. Skibińska A., Żółty M., Badanie możliwości modyfikacji stabilności termooksydacyjnej olejów bazowych. Nafta-Gaz, 71(5), 2015, 327-336.

8. BS 2000-142:1993 Methods of test for petroleum and its products. Determination of oxidation stability of lubricating grease. Oxygen bomb method.

9. FTM 791.3453 Oxidation Stability of Lubricating Grease by the Oxygen Bomb Method.

10. IP 142:2015 Determination of oxidation stability of lubricating grease - Oxygen pressure vessel method.

11. ASTM D 942-15 Standard Test Method for Oxidation Stability of Lubricating Greases by the Oxygen Pressure Vessel Method.

12. DIN 51808:2018-02 Testing of lubricants - Determination of oxidation stability of greases - Oxygen method.

13. PN-C-04143:1956 Przetwory naftowe - Smary stałe - Badanie odporności na utlenianie.

14. ASTM D 8206-18 Standard Test Method for Oxidation Stability of Lubricating Greases-Rapid Small-Scale Oxidation Test (RSSOT).

15. Azad S., Evans J., NLGI Spokesman, 78(6), 2015, 30-40.

16. Selby T., Evans J., Azad S., Van Bergen W., www.savantgroup.com/media/2014-Paper-Savant-Quantum-grease-D942-TAE.pdf (access 2018.09.07).

17. Edinger C., Petro-Online.com October/November Nov 04, 2016 (access: 2018-09-07).

18. Nolan S.J., Savin R., ELGI Paper - Venice 2016.

19. PN-EN ISO 3104 Petroleum products - Transparent and opaque liquids - Determination of kinematic viscosity and calculation of dynamic viscosity.

20. PN-ISO 2909 Petroleum products - Calculation of viscosity index from kinematic viscosity.

21. PN-ISO 2049 Petroleum products - Determination of colour (ASTM scale).

22. PN-ISO 3016 Petroleum and related products from natural or synthetic sources - Determination of pour poin.

23. PN-C-04049 Petroleum and related products - Determination of acid and basic number by potentiometric titration method.

24. PN-EN ISO 2592 Petroleum and related products - Determination of flash and fire points - Cleveland open cup method.

25. PN-ISO 2137:2011 Petroleum products and lubricants - Determination of cone penetration of lubricating greases and petrolatum.

26. PN-ISO 2176:2011 Petroleum products - Lubricating grease - Determination of dropping point. 